\title{
Construction and Practice of Training Project to Enhance the Animation Professional Comprehensive Ability Based on OBE-oriented +3-Center-Change-Creative
}

\author{
Ran Zhao ${ }^{\text {a }}$, Xuesong $\mathrm{Li}^{\mathrm{b}}$ \\ Dalian Neusoft University of Information, Dalian, Liaoning \\ a99373228@qq.com, b112814344@qq.com
}

Keywords: OBE Orientation; 3-Center-Change-Creative; Project Construction and Practice

\begin{abstract}
The CDIO engineering education reform is a great revival of China's higher engineering education. With it as the guiding principle, the TOPCARES-CDIO teaching reform is conceived, designed, implemented and operated. Combined with the OBE result orientation, TOPCARES-CDIO inspects the teaching effects through the results, continuously improves the training model of innovative and entrepreneurial application-oriented talents, adheres to the national original animation works based on the core concepts of "Culture Innovation Enhances National Cultural Soft Power", "Innovation and Entrepreneurship Education”, and "Promoting Employment by Entrepreneurship" proposed in the $3^{\text {rd }}$ five-year plan of China, and encourages students to exploit innovative thinking, actively participate in the entrepreneurship practices and promote the core values of socialism, boosting the realization of the Chinese Dream.
\end{abstract}

\section{Transformation from CDIO and TOPCARES-CDIO Engineering Education to OBE Project Result Orientation}

TOPCARES-CDIO is a process of 10 years' continuous learning, integration and innovation from the emergence of CDIO in China, to the CDIO for Training of Innovation and Entrepreneurial Talents", and is also an education model with the goal of cultivating innovative and entrepreneurial application-oriented talents based on the CDIO engineering education, combined with concept, design, implementation, operation educational ideas. The concept of CDIO engineering education was initiated by the Massachusetts Institute of Technology, was introduced to Shantou University in China from the University of Calgary, Canada, and even has been promoted to our whole country. With the cultivating higher engineering education talents as the starting point, it has been constantly improved, with combination of the actual development of local education in China. "Some colleges and universities have begun to promote the concept, idea, method, and experiences of the CDIO reform to non-engineering majors[1]" and put forward the education and teaching ideas of using practice to verify the truth, and use the achievements to verify the practical effects, to cultivate the phased industrial and applied talents; "TOPACRES is the combination of the first English letters of the 8 first-level competency indicators for students.[2]”TOPCARES-CDIO is the educational model and educational concept of Dalian Neusoft Institute of Information combining with the exploration and practice in its own the integrated talent training model. In 2012, the Institute leaders presented educational teaching ideas and achievements at the 8th International CDIO Engineering Conference. Passing the strict review by the Conference and the organization, they were formally accepted as a member of the organization and recognized by the international engineering education institutions. In the 9-year meticulous teaching, by continuously summing up results and training the talents to self-improve in the employment and the work position - the OBE (Out come-Based-Education) 
model teaching model stood out. It is an Output-oriented model as a basis for evaluation of teaching results, and also as a goal to promote the training objectives in the professional field, and continue the graduation requirements.[3]" What the animation-majored students have learned in the learning process and whether they can successfully find employment in the cultural industry and the media communication field, self-realization is far more important than the teaching process of traditional colleges and universities, i.e. when to learn and how to learn, which coincides with the OBE educational model.

\section{2 “3-Center-Change-Creative"}

"3-Center-Change-Creative" means the changes from the teacher-centered model to the student-centered model, from the textbook-centered model to the project-centered model, and from the classroom-centered model to the innovation and entrepreneurship-centered model. In the teaching process, students act as implementers, simulating entrepreneurship and completing the collection of data, plan formulation, program selection, system implementation, information feedback, and evaluation of results, and activating the gene of makers. The educational concept of "3-Center-Change-Creative" was first proposed by the animation professional education and management team of the Digital Art Department of Dalian Neusoft Institute of Information. It refers to the reform of professional teaching content and model with training the innovative application-oriented undergraduate talent as the objectives, combined with the TOPCARES-CDIO engineering education concept and OBE learning output model, students' actual cognition, acceptance and learning effects. The three centers are closely linked with each other, driving the results of the comprehensive training project, and making the project achievements and the graduation design of the first-class coping stone project form the progressively complementary relationship. In the contemporary society of popular innovation and people's entrepreneurship, the teaching mode of the "3-Center-Change-Creative" is fully integrated with the characteristics of the era and the trend of innovative application-oriented undergraduate education. The relationship is shown in Figure 1 below:

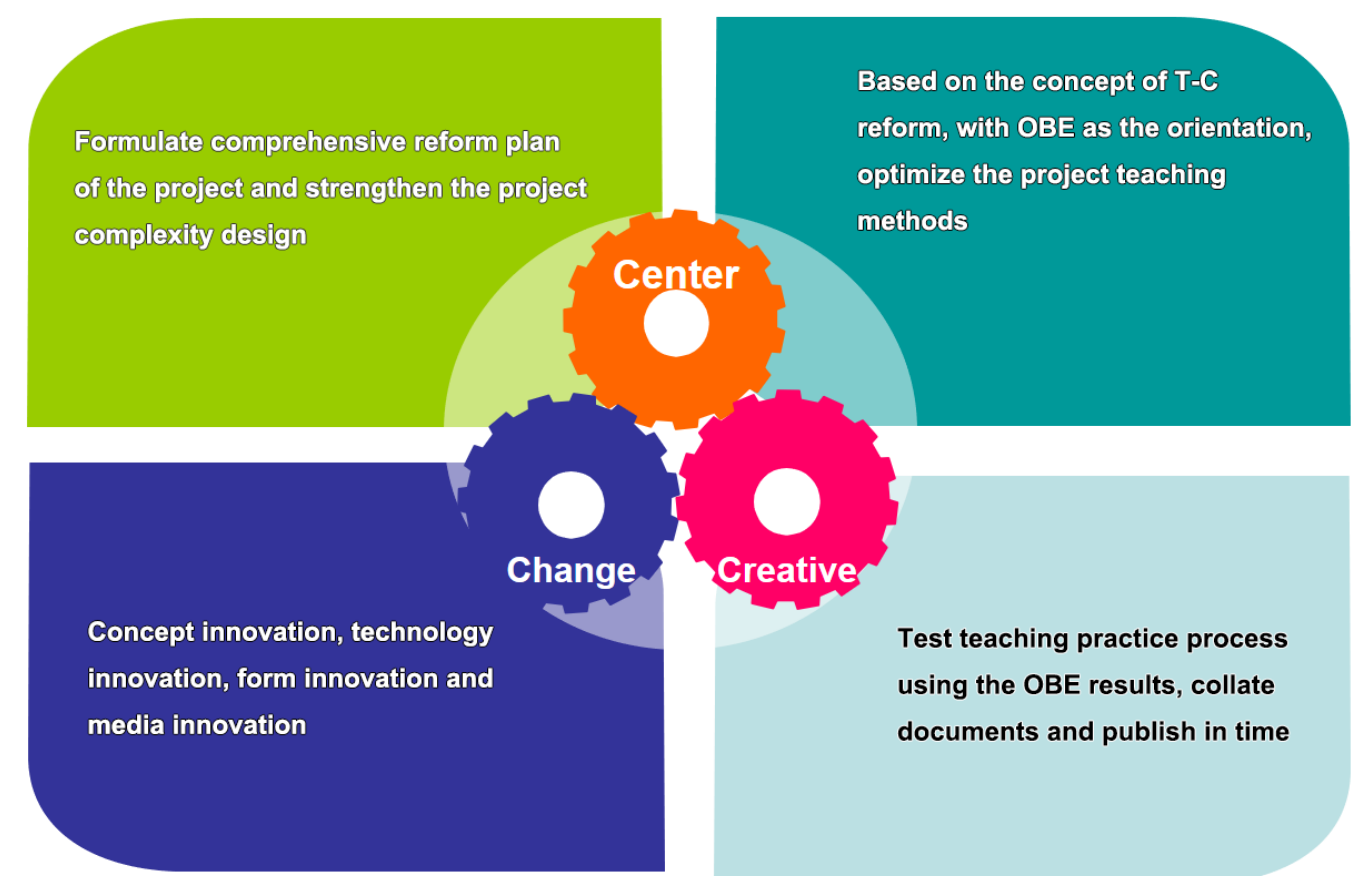

Figure 1 Chart for Relationship between 3-Center-Change-Creative and Talent Training Objectives 


\section{Construction Goals of Animation Professional Comprehensive Ability Training Project}

On the basis of "Establishing an Integrative TOPCARES-CDIO Talent Training Program with Knowledge, Competence, and Quality Training as the Core[4]”, the animation short film creation course not only serves as a top-level coping stone project, but also as a comprehensive professional training project, reflecting the "craftsman's spirit”. In the teaching process, teachers and students thoroughly analyze the successes and failures of original animated short films at home and abroad, and the original animation is the actual embodiment of "craftsman's spirit". With the successes of domestic original anime movies of Monkey King Hero Is Back, Big Fish \& Begonia, Da Hu Fa and Big World in terms of the word of mouth and at the box office, they have played an exemplary role in the teaching process on the aspects industry standards and values. Teachers and students have thoroughly analyzed the successes and failures of domestic original animation brands from the market to the theory. Students are guided to conduct research and statistics on theoretical data through CNKI, Wanfang, Google Academies and other databases, and carry out the big data analysis on aesthetic trends of the contemporary public, continue to practice, and profoundly realize the "craftsman's spirit”. After the design of original animation images is completed, the successful transformation of thinking - kind - products - brand may be realized by making full use of "new theories, new technologies, new tools, new methods" visualized products, with the assistance of the craft + , 2D animation, 3D animation studio, 3D Print Maker, augmented reality and video effects laboratories. The network survey on social job capabilities was carried out and the capability indicators needed for the project are initially established.

\section{Practice Process of OBE-based Animation Professional Comprehensive Training Project}

Under the orientation of the OBE education model, "students can clearly feel the expectations from the teacher and obtain an achievement experience through continuous formation evaluation.[5]" The animation professional comprehensive ability training project is a process in which learning output drives the entire teaching and examines the teaching effect. This relationship between driving and evaluation can be summarized from the following six aspects:

1) Professional basic courses, core courses, main courses, practical courses, and first-class projects run through the entire professional ability training goal. With the "fishbone diagram" approach to form the stage summary and progressive care, the students independently plan and assume the director role, with animated short film creation project as the orientation, combined with the basic courses such as art basics, character modeling, design principles, digital painting, three-dimensional modeling as the early-stage support, and with the courses like three-dimensional modeling, 3D character animation, animation post synthesis, character advanced animation, original animation, special effects animation as the ultimate support. Practical courses create an avatar image recognition system, character brand modeling elements, three-dimensional character presentation system, animation derivative product system, etc., and can effectively evaluate the works. The work set design and graduation design create original cartoon brands, running throughout the process of professional capacity training.

2) A practical teaching system that focuses on "producing, learning, and researching” in-depth cooperation is established. By understanding the development trends of domestic and foreign professions and the status quo of the industry, and clarifying the actual needs of the industry, practical projects have been carefully designed in the design of the integrated curriculum system. Each of the projects is supported by a number of major courses and guided by project training, 
achieving the integration of courses and projects and forming the integrated curriculum system with simultaneous training of knowledge, ability and quality. The SOVO (College Entrepreneurship Center) company was set up, and the project's outstanding works deepened the cooperation in production, education and research relying on the Digital Arts Department's space innovation and entrepreneurship experience platform. The joint training of schools and enterprises is realized by making use of the atmosphere advantage of Dalian Animation Industry Park. A practical training base outside school has been set. Besides, with the help of employment feedback from alumni of graduates, it has been expanded to Beijing, Shanghai, Guangzhou, and Shenzhen, as well as Hengdian Film and Television Base and other practical training bases with high industrial density.

3) Based on the multi-platform cooperation, the real animation derivative products project got the recognition via the competition platform. With the crowdfunding platform, Tencent and Ali platform, the cartoon original image and brand designed by the students are promoted and there they can take the customization business. At the same time, the works of some students have applied for appearance patents and the commercial transformation is under preparation. Some students' peripheral design products have 3D visualization features, and they can be printed in 3D using ABS, PLA, and resins. Some students' works can be efficiently molded, and published on the e-commerce platform for customization. These good feedbacks from the external environment, not only allow students to get the first pot of gold in life, but also play a demonstration role, inspiring students' entrepreneurial passion.

4) The interaction between learning and research cultivates students' extracurricular innovation and entrepreneurship ability relying on high-level events and vertical and horizontal projects. Professional teachers combine their own research direction, set up scientific research team, focus on students' expertise, allow students to participate in horizontal and vertical topics in a targeted way. At the same time, they select social professional competitions and actively organize and guide students to declare school level, provincial level and even national level college student innovation and entrepreneurship projects, production and research projects, cooperative education programs, etc.

5) The multi-level and multi-form training and exchanges are carried out, the "cross-media" integration and promotion has strengthened the peripheral animation product design projects. In order to effectively understand and master the "four new" in the industry, their awareness of innovation and entrepreneurship are enhanced. Relevant experts from the four major academies of the art industry and first-tier entrepreneurs and designers from the industry were invited to come to the institute to give lectures and provide training. The teachers of the project team also went to view and emulate animation industry exhibitions, participated in annual conferences on innovation and entrepreneurship, and academic conferences for exchange learning and corporate training. In the promotion of results, a cross-school joint animation industry-related seminar was held. Via the mobile platforms and mobile clients, the animated short films and students achievements in the derivative product design project were displayed. The self-developed augmented reality digital picture book was highly praised among the children's cognitive series picture books.

6) The quality of theoretical research results was enhanced, and excellent teaching materials formed. They actively participated in international conferences related to art education, published relevant research literature, positively developed relevant teaching materials, focused on daily archiving, formed electronic archives, continuously accumulated, combined the $13^{\text {th }}$ five-year plan to form influential teaching materials in the professional field, actively participated in international conferences related to high-end art education, and innovatively practiced the internationally 
advanced education concept in the classroom.

\section{Significance and Prospect}

With the development of TOPCARE-CDIO education and teaching concepts and teaching reform, the talents with good practical ability and patriotism, good humanistic values, and creative entrepreneurial ability are cultivated in terms of curriculum construction, based on the commercial standards of the cultural industry and the animation industry. As science and technology develop, the 3D printing technology, augmented reality technology, virtual reality technology, holographic projection technology and artificial intelligence technology have been introduced into the construction and practice of animation professional comprehensive ability training projects. For application-oriented university, training for application-oriented talents is the basis for personnel training. Chinese traditional culture, folk culture, and humanistic care are soaked in classroom teaching. Based on the "original” core, students' deep experience in Chinese dreams, Chinese spirit, and Chinese culture and local culture are emphasized and also integrated into their own works instead of simply superimposing symbol elements. Made in China 2025 has started. This is the process of realizing Chinese dream from "Made in China" to "Created in China", carrying the historic mission of the great rejuvenation of the Chinese nation. China's university education is ushering in popularization, so it should even take a lead in the era.

\section{Acknowledgement}

In this paper, the research was sponsored by Dalian Neusoft University of Information the education and teaching reform project in 2017.

\section{References}

[1] Gu Peihua, Research on the CDIO Development Path, Production Imaging and its Causes from CDIO in China to China's CDIO, Research in Higher Education of Engineering, 2017, vol. 1: p24-43.

[2] Wang Shiyong, Liu Long and Dong Yu, Evaluation of Students' Learning Effectiveness Based on TOPCARES-CDIO, Research in Higher Education of Engineering, 2014(6): 185-190

[3] Yang Yigang, Meng Bin and Wang Weinan, Cultivation of Technological Innovation Ability Based on OBE Model, Research in Higher Education of Engineering, 2015(6): 24-30

[4] Wen Tao, Exploration and Construction of Integrated TOPCARES-CDIO Talent Cultivation Model, China Higher Education, July 2011: 41-43

[5] Gu Peihua, Engineering Education Model Based on 'Observative Outputs' (OBE)_—Practice and Exploration of Shantou University, Research in Higher Education of Engineering, vol. 1, 2014: $27-37$ 